\title{
EDITORIAL
}

\section{The Science of the Permissible?}

The two major theories of moral philosophy which underpin medical moral philosophy, or medical ethics the terms may be used interchangeably - can be classified as deontological and utilitarian.

The word "deontological" is derived from the Greek deon, duty, and deontological theory maintains that the rightness or wrongness of human actions are not exclusively (and in extreme cases, not at all) related to their consequences, but that moral actions stem from duties. The best known exponent of deontological theory was the predominantly eighteenth century philosopher Immanuel Kant. One of the formulations of what Kant considered to be the "supreme principle of morality" (the Categorical Imperative) reads - "Act always in such a way that you treat humanity, whether in your own person or in the person of any other, never simply as a means, but always at the same time as an end". This is an ethics of respect for others, and Kant goes on to enunciate two types of duties which derive from this formulation.

Perfect duties are absolute. There is, for example, a perfect duty not to kill an innocent person (including oneself), not to tell lies, and not to break promises, for in committing any of these acts, an agent uses another person merely as a means. It may, of course, be permissible to use others as a means in certain situations; a doctor may use his patients as a means of obtaining of his livelihood, and a student may use his teachers as a means of obtaining his education, but the premise must be that those who are so used consent voluntarily.

Imperfect duties are much less strictly defined, and require basically the promotion of two goals - one's own self-development, and the welfare of others. No specific actions are called for, and there is room for personal choice.

Despite the apparent attractiveness of deontological theory, and its refinement over the years - not least by the twentieth century moral philosopher WD Ross there are undoubted difficulties with this system of moral philosophy in medical ethical thinking. For example, how should one act when two perfect duties conflict? How can a doctor act morally when, sworn to secrecy by a patient who has discussed suicide with him, he is asked by a relative of the patient if such a discussion took place?

In contrast to deontological theory, utilitarianism takes account of the consequences of human actions. It has its roots as early as Epicurus in the third century BC, but was developed to a large extent by two English philosophers in the eighteenth and nineteenth centuries - Jeremy Bentham and John Stuart Mill - and it is probably fair to say that much argumentation in medical ethics today is based on utilitarian reasoning.
The basic idea is that morality is all about maximising good (defined to include such concepts as any form of satisfaction or enjoyment) and minimising evil (including any form of dissatisfaction, frustration or displeasure). When confronted with a moral decision, one should first consider alternative pathways of action, then consider the consequences of each (which may be numerous and far-reaching), weigh the good against the bad, and then select the course of action which will result in the greatest balance of good over evil. Calculation is all important in this form of "situational ethics", and this in itself raises difficulties; how can one predict all the consequences of a given action, how can one assign weights to the various forms of human satisfaction, and, indeed, how can one find time to do all the calculations? It has also been argued that this simple "act utilitarianism" sets moral standards that are, in practice, too high, since every decision is based predominantly upon consideration of others. Neither does it always accord with our own moral experiences; the killing of terminally ill patient in pain may, inter alia, lessen the burden on his firm's pension fund, but, although this consideration is apparently demanded by utilitarian reasoning, no right-minded doctor would consider iț moral to take such factors into account in patienf management.

In order to overcome some of these difficulties another form of utilitarian theory - "rule utilitarianism, - has been advocated. The basic principle in this systemo may be stated thus: "Act in accordance with the rule that, if generally followed, would produce the greatest balance of good over evil, everyone considered". A moral code, constructed along utilitarian principles, now intervenes in the calculation to modify actions. For example, the rule "do not kill" is obviously more moral than the rule, "kill whenever you want to", but unlike the perfect duties of deontological theory, the former rule is capable of exceptions, such as "do not kill-except in self defence".

A system which permits exceptions to moral rules, and yet preserves a structured framework within which moral decisions can be made has obviously much to commend it in the increasing complexity of current medical practise.

But in addition to moral philosophical theory, it is also necessary to take note of some of the principles by which reasoning should be governed. Perhaps the most important of these are autonomy (and respect for autonomy), beneficence, non-maleficence, and justice. The limited space of an Editorial does not permit discussion of these in detail, and they are well covered in the books recommended, but some of the problems inherent in handling these apparently self-evident moral 
principles can be illustrated. How can one, for example, reconcile the duty to do good to others (beneficence) with respect for autonomy when the doctor's perception of what is best for the patient is at variance with that of the patient? If the principle of non-maleficence is absolute - primum non nocere - is it moral to use drugs with any potential for side effects?

Now, it has been suggested by some that a third system of moral philosophical theory could be added to the two already outlined - "legalistic" moral philosophy. The main thrust of this line of thought appears to be to remove any burden of moral decision making from the individual and place it wholly upon the lawmaker and the lawyer; that which is legal becomes moral, and that which is not legal becomes immoral. It may seem to some an attractive option, but it must be seen to be severely flawed. Medicine being a science based subject, develops ahead of public opinion and, indeed, helps to form it; such laws or regulations as would deal with the topics being considered here are usually based, at least in part, on public opinion, and therefore tend chronologically to follow its formation. In consequence, it is at the very time that guidance is needed that there is unlikely to be appropriate law to consult.
The complexity of medical practice today has already been cited, and it is that very complexity, together with the increasing effectiveness of treatment, thak necessitates consideration of moral, philosophical (and $\underset{\not D}{Z}$ indeed, legal) questions. It is surely naïve in the extremeo to assume that such problems will only presen 6 themselves to our civilian colleagues, and Army doctors should be encouraged to take an active and informed. interest in medical ethical matters. In January 1988, $\overrightarrow{\overrightarrow{\overrightarrow{5}}}$ pilot course on "Medical, Legal and Ethical Issues"? brought together at the Royal Army Medical College $\frac{D}{0}$ officers of a wide range of seniority from the Roya $\overline{5}$. Army Medical Corps, the Army Legal Corps and the Royal Army Chaplains' Department to discuss just such matters. The establishment of such meetings as a regulars feature would go some way towards fostering such anb interest.

\section{RECOMMENDED FURTHER READING}

Gillon R. Philosophical Medical Ethics. Chichester; New York: Wiley, 1986.

MapPes T A and Zembaty J S, Eds. Biomedical Ethics. New' York: McGraw Hill, 1986.

\section{NOTICE TO SUBSCRIBERS}

Space orders should be sent to Combined Service Publications Ltd., P.O. Box 4, Farnborough, Hampshire GU14 7LR. Artwork and/or Copy should be forwarded to the same address to arrive by the first day of the month preceding issue, publication dates being February, June and October of each year.

Advertising Rates and Technical Details are as listed in British Rate and Data. 